\title{
Seawater Degradation Resistance of Straw Fiber- reinforced Polyvinyl Chloride Composites
}

\author{
Liangpeng Jiang, ${ }^{\mathrm{a}}$ Jingjing $\mathrm{Fu},{ }^{\mathrm{b}}, *$ and Lihong Liu ${ }^{\mathrm{a}}$
}

To investigate the effect of seawater degradation on the mechanical, wear, and thermal properties of plant fiber-reinforced polymer composites, the seawater immersion test was performed on four types of straw fiber (wheat straw (WS), rice straw (RS), corn straw (CS), and sorghum straw (SS))reinforced polyvinyl chloride (PVC) composites. The results revealed that seawater immersion would result in poor mechanical, wear, and thermal properties, and lower two-phase bonding quality, thermal mass loss, and thermal residual mass, as well as more serious abrasive wear. The SS/PVC and CS/PVC composites had the highest and lowest seawater degradation resistance, respectively. After $12 \mathrm{~d}$ seawater immersion, the tensile strength of the SS/PVC and CS/PVC composites decreased from 17.3 to $9.7 \mathrm{MPa}$ and from 12.3 to $7.2 \mathrm{MPa}$, respectively; and the flexural strength of the SS/PVC and CS/PVC composites decreased from 34.2 to $20.1 \mathrm{MPa}$ and from 28.0 to $15.3 \mathrm{MPa}$, respectively. However, the friction coefficient of the SS/PVC and CS/PVC composites increased from 0.21 to 0.27 and from 0.24 to 0.30 , respectively; and the specific wear rate of the SS/PVC and CS/PVC composites increased from $0.73 \times 10^{-5} \mathrm{~mm}^{3} / \mathrm{N} \cdot \mathrm{m}$ to $21.7 \times 10^{-5} \mathrm{~mm}^{3} / \mathrm{N} \cdot \mathrm{m}$ and from $1.77 \times 10^{-5}$ to $28.3 \times 10^{-5} \mathrm{~mm} / \mathrm{N} \cdot \mathrm{m}$.

Keywords: Straw fibers; Polyvinyl chloride; Composites; Seawater degradation; Performance comparison

Contact information: a: School of Mechanical Engineering, Anhui University of Science and Technology, Huainan 232001, China; $b$ : Nanjing Institute of Agricultural Mechanization, Ministry of Agriculture and Rural Affairs, Nanjing 210014, China; *Corresponding author: tutujing12@163.com

\section{INTRODUCTION}

Plant fiber reinforced polymer composites (PFRPs) are biomaterials prepared by using plant fibers as reinforcement material and thermoplastics as matrix. Such composites have been widely applied in structural and construction areas, such as decking and fencing (Ku et al. 2011; Leu et al. 2012; Chen et al. 2018). Nevertheless, the hydrophilic character of plant fibers has caused some cases of PFRPs failures in outdoor service, especially in high humidity environments. The diffusion of water into the composites will destroy the bonding quality between fiber and matrix phases, which in turn will shorten their expected working life and durability. The study of PFRPs exposed to ultraviolet radiation (Chaochanchaikul et al. 2013), fungal-induced (Srimalanon et al. 2016), freeze thawing (Srubar 2015), soil burial (Kositchaiyong et al. 2014), and some conditions have already been intensely documented. With the discovery of the application potential of wood-plastic composite materials in the field of marine engineering, its seawater aging has attracted attention, and research has been carried out abroad (Yang et al. 2018). Yan and Chouw (2015) have investigated the anti-degradation of flax fabric/epoxy composites in water, seawater, and $5 \% \mathrm{NaOH}$ solution. The results showed that the degradation of mechanical properties followed the order: $5 \% \mathrm{NaOH}>$ seawater > water. Nosbi et al. (2010) studied the degradation of compressive properties of kenaf fiber-reinforced polyester composites 
in water, seawater, and acid rain condition, and they found that the decay in compressive properties can be attributed to the plasticization of fiber-matrix interface and swelling of kenaf fiber. Mazuki et al. (2011) studied the distilled water, seawater, and acid rain aging properties of kenaf/polyester composites. The degree of deterioration of dynamic mechanical properties was observed as: seawater $>$ acid rain $>$ distilled water. Le Duigou et al. (2014) and Nair et al. (2018) studied the seawater aging properties of flax / polylactic acid composites and coconut shell / sawdust / epoxy composites, respectively.

In the last few years, the authors explored the degradation resistance and wear behavior of sorghum straw/PVC composites in alternate simulated seawater and acid rain degradation conditions (Jiang et al. 2017, 2018, and 2019). The conclusions from these studies were that the salinity and temperature of seawater, the $\mathrm{pH}$, and temperature of acid rain could reduce the wear resistances of composites, and the reduction of contact of fibers with seawater and acid rain is the key point to enhance the serviceability of sorghum straw (SS)-polyvinyl chloride (PVC) composites. Herein, this work focuses on the comparison of degradation resistance of four different straw fibers (wheat straw (WS), rice straw (RS), corn straw (CS), and SS-reinforced PVC composites in seawater conditions. It is expected that the information obtained in this study could give a theoretical support for the preparation and application of anti-degradative PFRPs.

\section{EXPERIMENTAL}

\section{Materials}

The materials WS, RS, CS, and SS were collected from a local farm in Nanjing, China. Polyvinyl chloride (SG-5) was purchased from Tianye Group Co., Ltd., Xinjiang, China. Silane coupling agent (KH-550) was purchased from Chuangshi Chemical Additives Co., Ltd., Nanjing China. The composite stabilizer $\mathrm{Ca} / \mathrm{Zn}(603)$ and polyethylene (PE) wax (H-108) were purchased from Wenhua Chemical Pigment Co., Ltd., Shanghai, China.

\section{Preparation of Straw Fiber-reinforced PVC Composites}

The four kinds of air-dried straw fibers were crushed, ground, and sieved with a 100 -mesh screen $(149 \mu \mathrm{m})$. Their chemical constituents (tested according to the Van Soest washing method) and aspect ratios (measured by a LEXT OLS4100 3D laser microscope (OLYMPUS, Tokyo, Japan)) are listed in Table 1. XRD analysis were conducted using a X'Pert PRO X-ray diffractometer (PANalytical B.V., Netherlands) with a $\mathrm{Cu} \mathrm{K} \alpha$ radiation source $(\underline{\lambda}=0.15406 \AA)$. The spectra were collected at a speed of $0.33^{\circ} \cdot \mathrm{min}^{-1}$ in the range of 0 to $90^{\circ}$. The crystallinity index $(\mathrm{Cr} I)$ was calculated using equation,

$$
\operatorname{CrI}=\left[1-\left(I_{a m}-I_{002}\right)\right] \times 100
$$

where $I_{\mathrm{am}}$ : intensity of the amorphous phase at $18^{\circ}$, and $I_{002}$ : intensity of the crystalline phase at $22.5^{\circ}$.

The silane coupling agent $\mathrm{KH}-550$ ( $3 \mathrm{wt} \%$ of straw fiber) was dissolved in absolute ethanol $(1: 5, \mathrm{v}: \mathrm{v})$, and the diluent was sprayed evenly on the straw fibers. The straw fibers were subsequently allowed to air-dry for $12 \mathrm{~h}$ followed by oven-drying (DHG-9140A electro-thermostatic drum-wind drying oven; Dongmai Scientific Instrument Co., Ltd., Nanjing, China) at $90{ }^{\circ} \mathrm{C}$ for $12 \mathrm{~h}$. 
The silane-treated straw fibers, PVC, stabilizer, and PE wax were mixed in a mass ratio $=100: 100: 8: 5$ in an SBH-5L 3D linkage mixer (Xinbao Mechanical and Electrical Co., Ltd., Nanjing, China), followed by melt blending in a RM200C conical twin-screw extruder (Hapro Electric Technology Co., Ltd., Harbin, China). The screw temperatures were maintained at $150{ }^{\circ} \mathrm{C}, 155^{\circ} \mathrm{C}, 160{ }^{\circ} \mathrm{C}$, and $165^{\circ} \mathrm{C}$ for zones $1,2,3$, and 4 (from hopper to die), respectively. The rotational speed of the screws was set at $20 \mathrm{rpm}$. The extruded samples with the cross-sectional area of $7 \mathrm{~mm} \times 10 \mathrm{~mm}$ were cooled at an ambient temperature, and cut to the required dimensions for further performance testing.

Table 1. Chemical Constituents and Aspect Ratios of Four Kinds of Straw Fibers

\begin{tabular}{|c|c|c|c|c|c|c|}
\hline \multirow{2}{*}{ Fiber } & \multicolumn{3}{|c|}{ Chemical Constituents (wt\%) } & \multirow{2}{*}{ Crystallinity (\%) } & \multirow{2}{*}{ Aspect Ratios } \\
\cline { 2 - 5 } & Cellulose & Hemicellulose & Lignin & Ash & & \\
\hline WS & 45.32 & 19.69 & 12.49 & 5.03 & 41.3 & 3.95 \\
\hline RS & 38.94 & 20.95 & 6.92 & 3.40 & 40.6 & 3.81 \\
\hline CS & 32.34 & 26.65 & 15.42 & 7.13 & 37.2 & 3.27 \\
\hline SS & 42.37 & 22.63 & 14.84 & 5.12 & 53.5 & 4.64 \\
\hline
\end{tabular}

\section{Immersion Test of Straw Fibers-reinforced PVC Composites in Simulated Seawater Condition}

The simulated seawater and its chemical components were prepared following the standard ASTM G1141 (2013), and the results are shown in Table 2. In addition, $\mathrm{NaOH}$ was used to adjust the $\mathrm{pH}$ value of the solution to 8 . The immersion test of samples was carried out in a constant temperature water-bath $\left(35^{\circ} \mathrm{C}\right)$ using $\mathrm{HH}-600$ thermostatic water tank (Baidian Instrument Equipment Co., Ltd., Shanghai, China) by total immersion. This test was comprised of three cycles (each cycle was $4 \mathrm{~d}$, the total was $12 \mathrm{~d}$ ), and the simulated seawater was refreshed once a cycle. At the end of each cycle, the samples were removed from the solution and left to air-dry until a constant mass (defined by mass variation of less than $1 \%$ in a period of $24 \mathrm{~h}$ ) was reached. After air-drying, the composites were sealed and stored for further characterization analysis.

Table 2. The Chemical Components of Simulated Seawater

\begin{tabular}{|c|c|c|c|c|c|c|c|c|c|c|}
\hline Component & $\mathrm{NaCl}$ & $\mathrm{MgCl}_{2}$ & $\mathrm{Na}_{2} \mathrm{SO}_{4}$ & $\mathrm{CaCl}_{2}$ & $\mathrm{KCl}$ & $\mathrm{NaHCO}_{3}$ & $\mathrm{KBr}$ & $\mathrm{H}_{3} \mathrm{BO}_{3}$ & $\mathrm{SrCl}_{2}$ & $\mathrm{NaF}$ \\
\hline $\begin{array}{c}\text { Concentration } \\
\left(\mathrm{g} \cdot \mathrm{L}^{-1}\right)\end{array}$ & 24.53 & 5.20 & 4.09 & 1.16 & 0.695 & 0.201 & 0.101 & 0.027 & 0.025 & 0.003 \\
\hline
\end{tabular}

\section{Methods}

The tensile and flexural strengths of samples were measured using a CMT6104 electronic universal testing machine (MTS Industrial Systems Co., Ltd., Shanghai, China) at a loading speed of $2 \mathrm{~mm} / \mathrm{min}$ at room temperature. The mean of five replicates was reported.

Wear performance was studied by means of a dry-sliding wear test according to GB/T 3960 (2016). A ring-on-block tribo machine (M-2000A; Xuanhua Kehua Testing Machine Manufacturing Co., Ltd., Zhangjiakou, China) was used at a load of $200 \mathrm{~N}$ and at a sliding speed of $200 \mathrm{rpm}$ for $30 \mathrm{~min}$. A quench-hardened $45^{\#}$ steel ring (outer diameter: $40 \mathrm{~mm}$ ) was employed as the counterpart with a surface hardness of 40 to $45 \mathrm{HRC}$ and a surface roughness of $0.08 \mu \mathrm{m}$ to $0.12 \mu \mathrm{m}$. Prior to each test, the samples and counterpart were cleaned with absolute ethanol to avoid undesirable impurities. Average friction 
coefficients $(\mu)$ were recorded automatically. The specific wear rate $\left(W_{\mathrm{s}}\right)$ was quantified using the following equation:

$$
W_{\mathrm{s}}=\Delta M /(L \cdot F \cdot \rho)
$$

where $\Delta M$ is the weight loss (mg), which was measured using a FA1004 electronic analytical balance (Hengping Scientific Instrument Co., Ltd., Shanghai, China) with an accuracy of $0.1 \mathrm{mg}$. The parameter $L$ denotes the sliding distance $(\mathrm{m}), F$ is the normal load $(\mathrm{N})$, and $\rho$ is the bulk density of samples $\left(\mathrm{g} \cdot \mathrm{cm}^{-3}\right)$ measured by a DH-300 direct-reading electronic densimeter (Dahometer Instrument Co., Ltd., Dongguang, China). Three replicates $(6 \mathrm{~mm} \times 7 \mathrm{~mm} \times 30 \mathrm{~mm})$ were tested for each straw fiber-reinforced PVC composite.

The morphology of tensile fracture and wear surfaces were identified using a scanning electron microscope (SEM, S-4800; Hitachi Ltd., Tokyo, Japan) equipped with an energy dispersive spectroscope (EDS). The detected surfaces were sputter-coated (E1010; Hitachi Ltd., Tokyo, Japan) with gold-palladium and operated at $3 \mathrm{kV}$. Each sample characterized at the size of $100 \mu \mathrm{m}$ level, the magnification was 500 .

Thermogravimetric (TG) analysis was performed using a STA 449 F3 synchronized thermal analyzer (NETZSCH Scientific Instrument Trading Co., Ltd., Selb, Germany) under an argon atmosphere. Samples of $5 \mathrm{mg}$ to $10 \mathrm{mg}$ were placed in an alumina crucible, heated from $30{ }^{\circ} \mathrm{C}$ to $800{ }^{\circ} \mathrm{C}$ at a heating rate of $20{ }^{\circ} \mathrm{C} / \mathrm{min}$. The test environment was $\mathrm{Ar}$ inert gas and the flow rates of shielding and sweep gases were kept at $20{ }^{\circ} \mathrm{C} / \mathrm{min}$ and 60 ${ }^{\circ} \mathrm{C} / \mathrm{min}$, respectively.

\section{RESULTS AND DISCUSSION}

\section{Mechanical Properties of Straw/PVC Composites}

Mechanical properties of straw/PVC composites measured are shown in Fig. 1. It can be seen that under the same immersion cycle, the tensile and flexural strengths of four different straw fiber-reinforced PVC composites presented the following trend: SS > WS $>\mathrm{RS}>\mathrm{CS}$. Moreover, this phenomenon occurred in each exposure period. This behavior might be ascribed to the high cellulose content and crystallinity of each fiber. Generally, the fiber with higher cellulose content and crystallinity could possess better strength and rigidity (Cai et al. 2016; Jiang et al. 2018). Further, the fiber with larger aspect ratio is equipped with abundant crosslinking of the fiber structural network, so that they have lower chance of agglomeration formed by hydrogen bonding. In other words, the straw fiber with higher cellulose content, crystallinity, and larger aspect ratio could exhibit an enhanced effect when serving as the reinforcement for the plastic matrix. Based on the data of Table 1, the cellulose content from high to low were as follows: WS $>$ SS $>$ RS $>$ CS, and the crystallinity and aspect ratio trends were: $\mathrm{SS}>\mathrm{WS}>\mathrm{RS}>\mathrm{CS}$. The tendency of the mechanical properties of four different straw fiber-reinforced PVC composites were highly consistent with the distribution of cellulose content, crystallinity, and aspect ratio.

With lengthening immersion cycles, all straw/PVC composites exhibited larger degradation of mechanical properties. In comparison with composites not exposed to seawater, the tensile strengths of WS/PVC, RS/PVC, CS/PVC, and SS/PVC decreased $46.3 \%, 44.2 \%, 41.1 \%$, and $44.0 \%$ after $12 \mathrm{~d}$ seawater immersion. Their flexural strength decreased $45.7 \%, 47.1 \%, 45.4 \%$, and $41.4 \%$, respectively. The explanation of the decreasing mechanical properties might involve two aspects. One was the water swelling 
of fibers, which formed microcracks and debonding between the interface of fiber and matrix (fracture surface could be observed in SEM images). The presence of microcracks limited the ability to transfer the stress from matrix to fiber. The other reason was that the seawater molecules played as a "swelling agent" role in the cellulose network structure, which led to more freedom of movement, damaging the non-deformability of the cellulose structure (Dhakal et al. 2007).
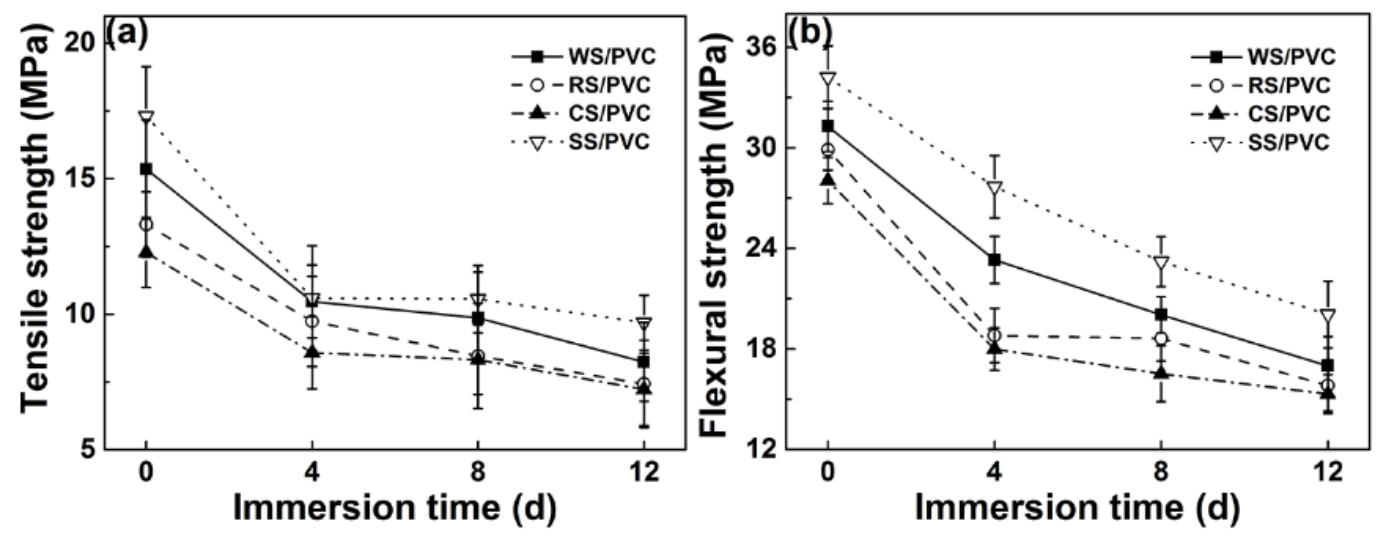

Fig. 1. Mechanical properties of straw/PVC composites: (a) Tensile strength and (b) flexural strength

\section{Tensile Fracture Surfaces Morphology of Straw/PVC Composites}

The CS/PVC composite, which exhibited the worst mechanical properties, and the SS/PVC, which had the best mechanical properties, were selected for the SEM analysis of tensile-fractured surfaces (Fig. 2). Before seawater immersion, few fibers were exposed on the surface, and the fibers still had good bonding with matrix. This phenomenon was observed in both CS/PVC and SS/PVC composites (Figs. 2a and 2c). After $12 \mathrm{~d}$ immersion, some fibers were pulled out of the matrix and large voids were formed in both composites (Figs. $2 b$ and $2 d$ ).

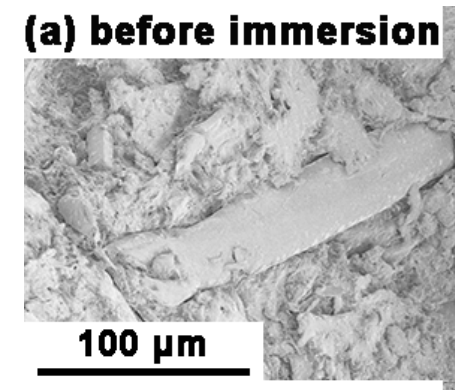

(c) before immersion

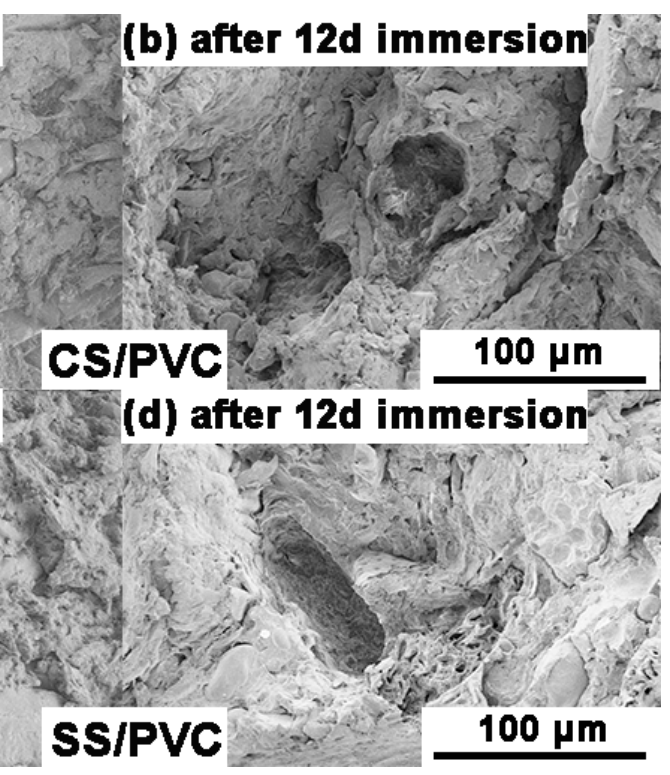

Fig. 2. SEM micrographs of the tensile fractured surfaces of CS/PVC and SS/PVC composites 
The tensile stress caused by the fiber absorbing water causes shear failure of the two interlocks, resulting in a change in morphology. In addition to the above observation, some long "gullies" appeared in the CS/PVC composite, while SS/PVC composite had smoother and flatter surfaces. This indicated that the SS/PVC composite had better interfacial interaction between fibers and matrix than the CS/PVC composite. The appearance of more fractures and voids resulted in poorer bonding quality in the two phases and lower rigidity of fibers, which directly corresponded with degraded mechanical properties. Those findings verified the analysis of mechanical properties.

\section{Wear Performance of Straw/PVC Composites}

The friction coefficient and specific wear rate of straw/PVC composites are presented in Fig. 3. The highest friction coefficient and specific wear rate were found in $\mathrm{CS} / \mathrm{PVC}$ composites among the four different straw fiber-reinforced PVC composites in each seawater immersion cycle, followed by RS/PVC, WS/PVC, and SS/PVC. The higher the friction coefficient and specific wear rate, the worse wear resistance of material that was observed. Under the same loading, the composites with higher structural strength would have fewer practical contacts on the friction interface, which induced lower sliding resistance and less removal of material (Shalwan and Yousif 2013). Based on the above observation, the structural strength (namely tensile and flexural strengths) of SS/PVC, WS/PVC, RS/PVC, and CS/PVC decreased gradually. In contrast, the fibers in a composite could play a support role at the adhesive interface, which could help bear the loading and prevent the abrasive particles from embedding and plowing the composite (Zhang et al. 2017). That is to say the fibers with high strength and rigidity could make the composite hardly appear fractured and have good point support function to the matrix. As aforementioned, SS and WS had better strength rigidity, followed by RS and CS (concluding according to the cellulose content and crystallinity). Therefore, the friction and specific wear rates of four different straw fiber-reinforced PVC composites were greatly influenced by the cellulose content and crystallinity of straw fibers.
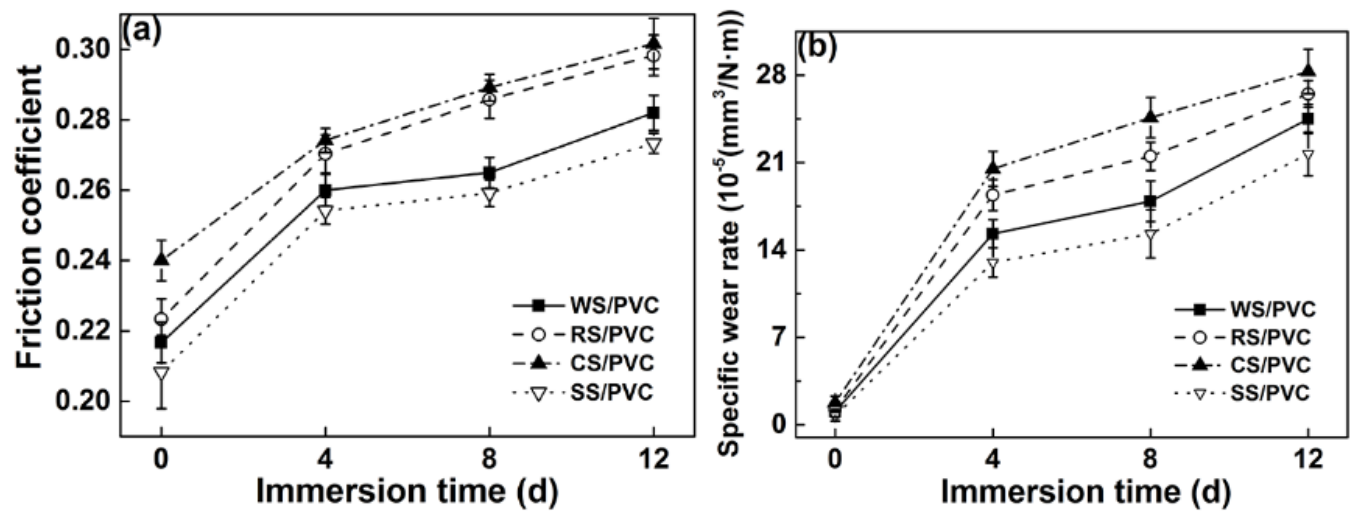

Fig. 3. Wear performances of straw/PVC composites: (a) Friction coefficient and (b) specific wear rate

It also could be found that the friction and specific wear rates of straw fiberreinforced PVC composites increased with increasing immersion period. Under the long seawater immersion period, the strength and rigidity of fibers, and the interfacial bonding of the two phases became weaker, which caused less adhesive loading on the fibers. This caused easy breaking into dissociative adhesive particles simultaneously. The weaker 
bonding quality could also bring declining grip-force from matrix to fibers. Fibers were easily pulled out into dissociative particles.

\section{Wear Surface Morphology of Straw/PVC Composites}

The CS/PVC with the worst wear performance and the SS/PVC with the best wear performance were selected for the SEM analysis of worn surfaces (Fig. 4). It could be seen that the worn surface of straw/PVC composites mainly consisted of abrasive wear. According to the principles of tribology, there are three reasons for the formation of abrasive wear. First, the micro-convex body on the surface of the counterpart wedged into the wear surface and formed a furrow. Only part of the material in the furrow was accumulated at the front of the wedge, and more of it was transferred to two sides to form a furrow (Günzel et al. 2002). Second, the free fibers held between the metal counterpart and the hard matrix moved at high speed under the environment of high temperature and high load friction. After repeated actions, such as compression and kneading, it was finally agglomerated into an "incompressible mass" (namely strain hardening). Then, the soft fibers were transformed into hard abrasive particles (Wu et al. 2007). The third reason was the hard sand and gravel particles that were not sufficiently removed during processing could also be used as abrasive particles to participate in abrasive wear. In comparison with CS/PVC, SS/PVC had weaker abrasive wear characteristics (such as the furrow and agglomeration). This behavior was ascribed to the higher structural strength of SS fiber and better interfacial bonding quality of SS/PVC composite. Seawater had less degradation resistance effect on SS/PVC than CS/PVC, so that the SS fibers were not easily cracked or pulled out to form free adhesive particles.
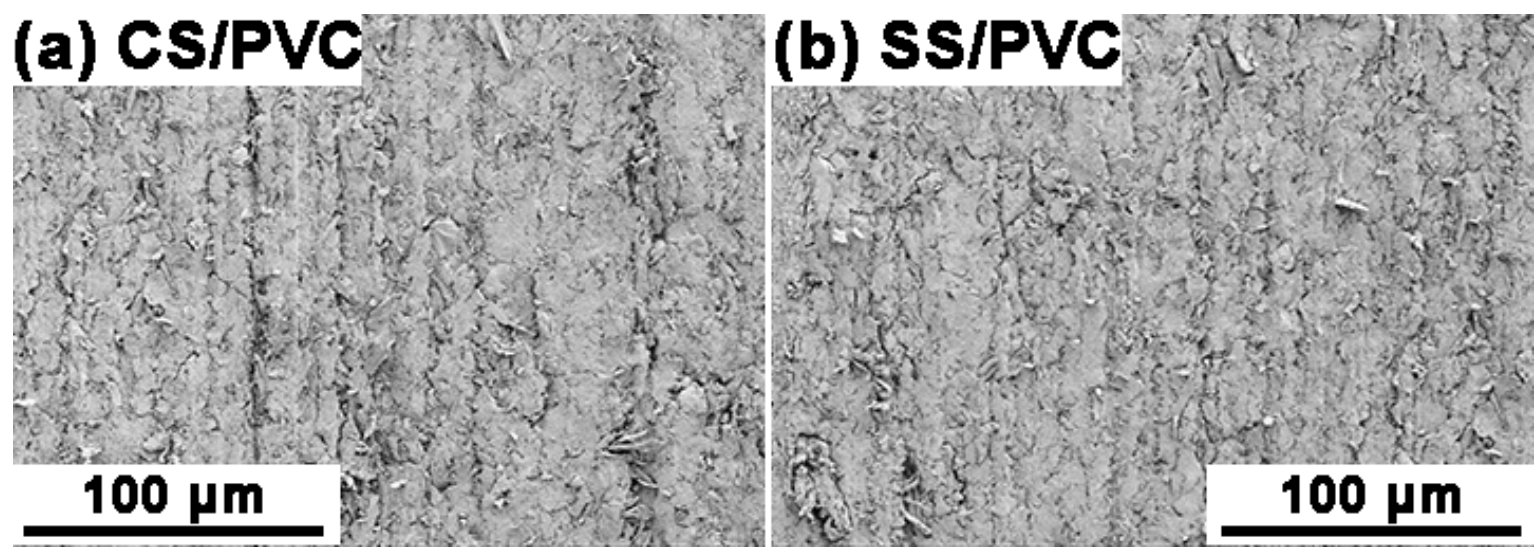

Fig. 4. SEM micrographs of the worn surfaces of CS/PVC and SS/PVC composites

\section{TG Analysis of Straw/PVC Composites}

The TG curves of straw/PVC composites are given in Fig. 5, and the main parameters of the pyrolysis process are listed in Table 3. Four different straw fiberreinforced PVC composites displayed similar pyrolysis tendency. They all had three stages of degradation (Cai et al. 2011): First stage (temperature lower than $150{ }^{\circ} \mathrm{C}$ and weight loss lower than $5 \%)$ was the drainage of free and bound water. Second stage $\left(250{ }^{\circ} \mathrm{C}\right.$ to $340{ }^{\circ} \mathrm{C}$, it was the first stage of pyrolysis) with a weight loss of approximately $50 \%$, which was attributed to the decomposition of cellulose, hemicellulose, and lignin. Simultaneously, the PVC matrix underwent dehydrochlorination (elimination of $\mathrm{HCl})(\mathrm{Fu}$ et al. 2016; Yu et al. 2016). The third stage of the temperature range from $430{ }^{\circ} \mathrm{C}$ to 485 
${ }^{\circ} \mathrm{C}$ and the weight loss between $15 \%$ and $20 \%$ was the second stage of pyrolysis. At this stage the breakage of conjugated double bonds of PVC occurred after elimination of $\mathrm{HCl}$. It should be noted that $\mathrm{TG}$ curves of temperature ranges between $340{ }^{\circ} \mathrm{C}$ to $430{ }^{\circ} \mathrm{C}$ and 500 ${ }^{\circ} \mathrm{C}$ to $800{ }^{\circ} \mathrm{C}$ were flatter (slight weight loss), which represented the further pyrolysis of lignin and carbonization of residues, respectively.

It could be seen from Table 3 that under the same immersion cycle, the highest onset degradation temperature of the first and second stages of pyrolysis was SS/PVC composite, followed by WS/PVC, RS/PVC, and CS/PVC composites. In addition, $12 \mathrm{~d}$ corrosion decreased the onset and terminal temperature of straw/PVC composites in the first and second stages of pyrolysis. Thermal stability of straw/PVC composites could be connected to the bonding quality of the two phases. The composite with better interfacial compatibility could effectively transfer the heat from matrix to fibers. Fiber's absorption of heat strengthened the matrix's resistance to thermal fluidity. It can be seen from the previous section that the aspect ratio of SS, WS, RS, and CS fibers decreased in that order, which means that the probability of agglomeration due to hydrogen bonding and further formation of bad interfaces between two phases increased in sequence. At the same time, seawater immersion played a role of deteriorating the combined quality of two phases.

It could also be found in Table 3 that after $12 \mathrm{~d}$ of degradation, the weight loss of the first and second stages of pyrolysis and the residual mass decreased for straw/PVC composites in comparison with nondegraded composites. The explanation could be that seawater exposed to the composite material had degraded the fibers, but it also had the function of "modifying the fibers". In that respect, seawater immersion can be regarded as being similar to alkali treatment. Based on this, it is inferred that the partial removal of non-cellulosic materials (hemicellulose and lignin) contained in straw fibers after seawater modification is the reason for the reduction in weight loss in the first and second pyrolysis stages. At the same time, non-cellulosic material removal also reduced the possibility of forming more pyrolysis residues.

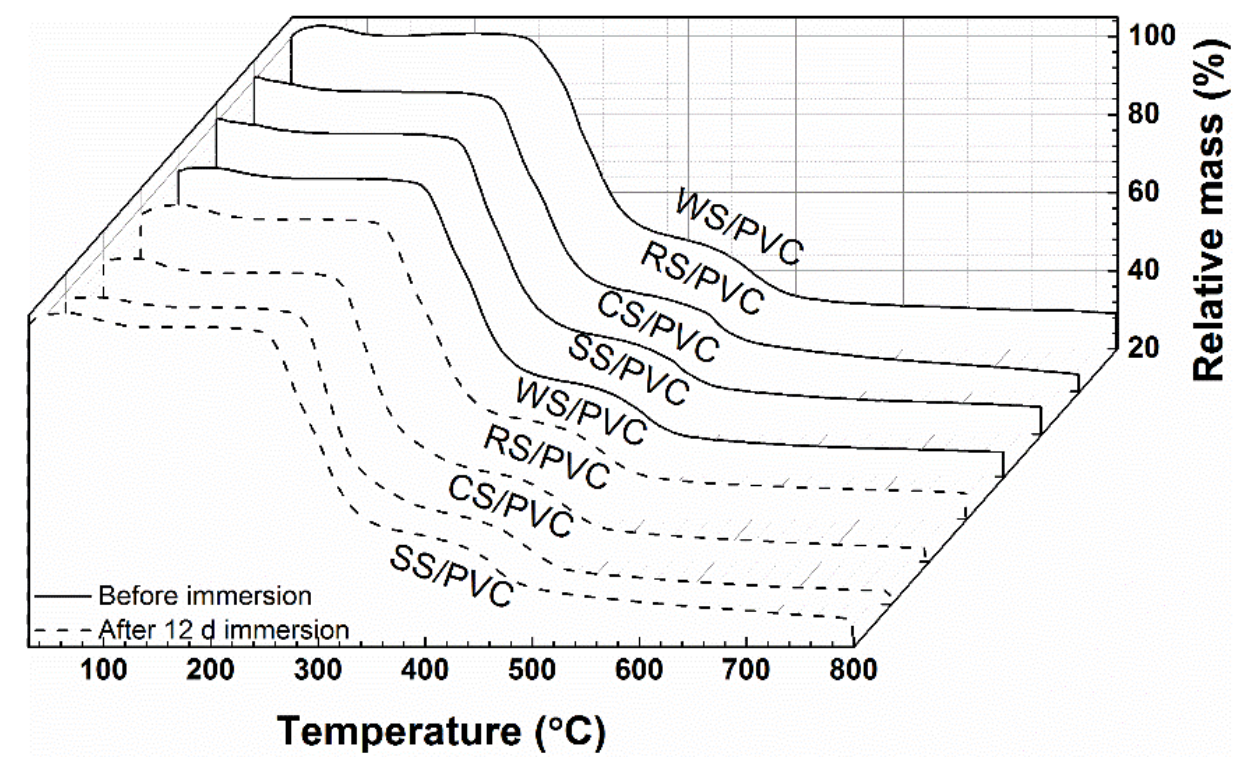

Fig. 5. TG curves of the straw/PVC composites 
Table 3. Pyrolysis Characteristic Data of the Straw/PVC Composites

\begin{tabular}{|c|c|c|c|c|c|c|c|c|}
\hline \multirow{4}{*}{ Sample } & \multirow{4}{*}{$\begin{array}{c}\text { Immersion } \\
\text { Time (d) }\end{array}$} & \multicolumn{7}{|c|}{ Pyrolysis Process } \\
\hline & & \multicolumn{3}{|c|}{ First Stage } & \multicolumn{3}{|c|}{ Second Stage } & \multirow{3}{*}{$\begin{array}{l}\text { Residual } \\
\text { Mass (\%) }\end{array}$} \\
\hline & & \multicolumn{2}{|c|}{ Temperature $\left({ }^{\circ} \mathrm{C}\right)$} & \multirow{2}{*}{$\begin{array}{c}\text { Mass } \\
\text { Loss } \\
(\%)\end{array}$} & \multicolumn{2}{|c|}{ Temperature $\left({ }^{\circ} \mathrm{C}\right)$} & \multirow{2}{*}{$\begin{array}{c}\text { Mass } \\
\text { Loss } \\
(\%)\end{array}$} & \\
\hline & & Onset & Termination & & Onset & Termination & & \\
\hline \multirow{2}{*}{ WS/PVC } & 0 & 256.2 & 335.9 & 52.2 & 433.5 & 476.0 & 18.1 & 29.2 \\
\hline & 12 & 250.1 & 322.9 & 50.8 & 427.4 & 469.4 & 16.8 & 26.9 \\
\hline \multirow{2}{*}{$\mathrm{RS} / \mathrm{PVC}$} & 0 & 254.9 & 330.8 & 51.8 & 433.1 & 470.2 & 20.6 & 27.4 \\
\hline & 12 & 249.8 & 324.3 & 51.4 & 425.7 & 462.5 & 17.0 & 22.2 \\
\hline \multirow{2}{*}{ CS/PVC } & 0 & 252.8 & 330.2 & 52.3 & 432.6 & 468.2 & 19.8 & 27.3 \\
\hline & 12 & 248.8 & 323.3 & 50.4 & 425.0 & 461.1 & 16.8 & 26.9 \\
\hline \multirow{2}{*}{ SS/PVC } & 0 & 258.3 & 334.6 & 52.2 & 437.8 & 481.7 & 17.6 & 26.2 \\
\hline & 12 & 252.1 & 329.6 & 50.5 & 432.3 & 477.5 & 14.5 & 23.2 \\
\hline
\end{tabular}

\section{CONCLUSIONS}

1. The seawater immersion caused the decline of the mechanical properties, wear performance, and thermal stability of straw fiber (WS, RS, CS, and SS)-reinforced PVC composites. Cellulose content, crystallinity, and aspect ratio of straw fibers were the main factors that influenced the performance of fibers when bonding with PVC matrix, and they further influenced the performance of straw/PVC composites. In comparison with four different straw/PVC composites, SS/PVC composite had the highest seawater degradation resistance, while CS/PVC composite exhibited the lowest.

2. The seawater immersion caused the degradation of the two phases of bonding quality of straw/PVC composites, which induced the decrease of mechanical properties. The tensile strengths of WS/PVC, RS/PVC, CS/PVC, and SS/PVC decreased $46.3 \%$, $44.2 \%, 41.1 \%$, and $44.0 \%$ after $12 \mathrm{~d}$ seawater immersion, and the flexural strength decreased $45.7 \%, 47.1 \%, 45.4 \%$, and $41.4 \%$, respectively. The worn surface of straw/PVC composites was mainly dominated by abrasive wear. Wear performance and thermal stability of straw/PVC composites had a close relationship with the structural strength of fiber and the interfacial compatibility of matrix and fiber. High structural strength of fiber and good interface bonding of two phases would endow the composites with better wear resistance and thermal stability.

\section{ACKNOWLEDGMENTS}

This work was supported by the School-level Programs for the Anhui University of Science and Technology (QN2019103) and the Biomass Conversion and Utilization Equipment Innovative Research Group of Science and Technology Innovative Engineering of Chinese Academy of Agricultural Science. 


\section{REFERENCES CITED}

ASTM G1141 (2013). "Standard practice for the preparation of substitute ocean water," ASTM International, West Conshohocken, PA, USA.

Cai, M., Takagi, H., Nakagaito, A. N., Li, Y., and Waterhouse, G. I. N. (2016). "Effect of alkali treatment on interfacial bonding in abaca fiber-reinforced composites," Composites Pt. A: Appl. Sci. Manufac. 90, 589-597. DOI: 10.1016/j.compositesa.2016.08.025.

Cai, P., Lu, Q., Liang, M., and Lai, G. (2011). "Effect of main components on the linear thermal expansion coefficient of wood-plastic composite," Plastics 40(6), 79-82, 86.

Chaochanchaikul, K., Rosarpitak, V., and Sombatsompop, N. (2013). "Photodegradation profiles of PVC compound and wood/PVC composites under UV weathering," Express Polymer Letters 7(2), 146-160. DOI: 10.3144/expresspolymlett.2013.14

Chen, J., Zou, Y., Ge, H., Cui, Z., and Liu, S. (2018). "Mechanical and water absorption behaviors of corn stalk/sisal fiber-reinforced hybrid composites," Journal of Applied Polymer Science 135(26), Article number 46405. DOI: 10.1002/app.46405

Dhakal, H., Zhang, Z., and Richardson, M. (2007). "Effect of water absorption on the mechanical properties of hemp fibre reinforced unsaturated polyester composites," Compos. Sci. Technol. 67(7-8), 1674-1683. DOI: 10.1016/j.compscitech.2006.06.019

Fu, J., He, C., Chang, X., Wang, X., Xiong, J., and Liu, J. (2016). "Thermo-stability and microstructure of wheat straw/polypropylene foamed composites," Act Materiae Compositae Sinica 33(03), 469-476. DOI: 10.13801/j.cnki.fhclxb.20150615.001

GB/T 3960 (2016). "Test method for friction and wear of plastics by sliding," Standardization Administration of China, Beijing, China.

Günzel, R., Rogozin, A. I., and Astrelin, V. T. (2002). "Fast, uniform, and large-scale heat treatment by plasma-based electrons," Vacuum 65(1), 59-65. DOI: 10.1016/S0042-207X(01)00406-7

Jiang, L., He, C., Fu, J., and Chen, D. (2017). "Wear behavior of wood-plastic composites in alternate simulated sea water and acid rain corrosion conditions," Polymer Testing 63, 236-243. DOI: 10.1016/j.polymertesting.2017.08.031

Jiang, L., He, C., Fu, J., and Wang, L. (2018). "Serviceability analysis of wood-plastic composites impregnated with paraffin-based Pickering emulsions in simulated sea water-acid rain conditions," Polymer Testing 70, 73-80. DOI: 10.1016/j.polymertesting.2018.06.031

Jiang, L., He, C., Fu, J., and Li, X. (2018). "Wear behavior of alkali-treated sorghum straw fiber reinforced polyvinyl chloride composites in corrosive water conditions," BioResources 13(2), 3362-3376. DOI: 10.15376/biores.13.2.3362-3376.

Jiang, L., He, C., Fu, J., and Xu, D. (2019). "Enhancement of wear and corrosion resistance of polyvinyl chloride/sorghum straw-based composites in cyclic sea water and acid rain conditions," Construction and Building Materials 223, 133-141. DOI: 10.1016/j.conbuildmat.2019.06.216

Kositchaiyong, A., Rosarpitak, V., Hamada, H., and Sombatsompop, N. (2014). "Antifungal performance and mechanical-morphological properties of $\mathrm{PVC}$ and wood/PVC composites under UV-weathering aging and soil-burial exposure," Int. Biodeterioration \& Biodegradation 91, 128-137. DOI: 10.1016/j.ibiod.2014.01.022

Ku, H., Wang, H., Pattarachaiyakoop, N., and Trada, M. (2011). "A review on the tensile properties of natural fiber reinforced polymer composites," Composites Part B: Engineering 42(4), 856-873. DOI: 10.1016/j.compositesb.2011.01.010 
Le Duigou, A., Bourmaud, A., Davies, P., and Baley, C. (2014). "Long term immersion in natural seawater of flax/PLA biocomposite," Ocean Engineering 90, 140-148. DOI: 10.1016/j.oceaneng.2014.07.021.

Leu, S., Yang, T., Lo, S., and Yang, T. (2012). "Optimized material composition to improve the physical and mechanical properties of extruded wood-plastic composites (WPCs)," Const. Build. Mater. 29, 120-127. DOI:

10.1016/j.conbuildmat.2011.09.013

Mazuki, A. A. M., Akil, H. M., Safiee, S., Ishak, Z. A. M., and Bakar, A. A. (2011). "Degradation of dynamic mechanical properties of pultruded kenaf fiber reinforced composites after immersion in various solutions," Composites Part B: Engineering 42(1), 71-76. DOI: 10.1016/j.compositesb.2010.08.004.

Nair, M. M., Shetty, N., Shetty, S. D., and Kamath, M. S. (2018). "Effect of distilled and sea water absorption on mechanical behaviour of short coir fibre epoxy composite/sawdust filler," Pertanika Journal of Sci. \& Technol. 26(1), 261-282.

Nosbi, N., Akil, H. M., Mohd Ishak, Z. A., and Abu Bakar, A. (2010). "Degradation of compressive properties of pultruded kenaf fiber reinforced composites after immersion in various solutions," Materials \& Design 31(10), 4960-4964. DOI: 10.1016/j.matdes.2010.04.037

Shalwan, A., and Yousif, B. F. (2013). "In state of art: Mechanical and tribological behaviour of polymeric composites based on natural fibres," Materials \& Design 48, 14-24. DOI: 10.1016/j.matdes.2012.07.014

Srimalanon, P., Yamsaengsung, W., Kositchaiyong, A., Wimolmala, E., Isarangkura, K., and Sombatsompop, N. (2016). "Effects of UV-accelerated weathering and natural weathering conditions on anti-fungal efficacy of wood/PVC composites doped with propylene glycol-based HPQM," Express Polymer Letters 10(4), 289-301. DOI: 10.3144/expresspolymlett.2016.27

Srubar, W. V. (2015). "An analytical model for predicting the freeze-thaw durability of wood-fiber composites," Composites Part B: Engineering 69, 435-442. DOI: 10.1016/j.compositesb.2014.10.015

Wu, J., Huang, J., Zhang, W., and Zhao, W. (2007). "Friction and wear behavior of the metals by Alfalfa powder," Tribology 27(1), 88-90. DOI: 10.16078/j.tribology.2007.01.019

Yan, L., and Chouw, N. (2015). "Effect of water, seawater and alkaline solution ageing on mechanical properties of flax fabric/epoxy composites used for civil engineering applications," Const. Build. Mater. 99, 118-127. DOI: 10.1016/j.conbuildmat.2015.09.025

Yang, M. F. M., Hamid, H., and Abdullah, A. M. (2018). "Potential use of cellulose fibre composites in marine environment-A review," in: Engineering Applications for New Materials and Technologies, A. Öchsner (ed.), Springer Int. Publishing, pp. 25-55.

Yu, J., Sun, L., Ma, C., Qiao, Y., and Yao, H. (2016). "Thermal degradation of PVC: A review," Waste Management 48, 300-314. DOI: 10.1016/j.wasman.2015.11.041

Zhang, K., Jiang, L., and Yao, Y. (2017). "Experiment of white iron abrasive wear for wheat grain powder," J. Chinese Cereals and Oils Association 32(1), 109-112.

Article submitted: March 12, 2020; Peer review completed: May 9, 2020; Revised version received and accepted: May 17, 2020; Published: May 20, 2020.

DOI: 10.15376/biores. 15.3.5305-5315 